\title{
Quantitative Estimation of Acid and Base from Locally Available Materials by Using Titration Method
}

\author{
Murugan Thirumalai \\ Department of Basic Sciences, St Joseph University in Tanzania, Ubungo, Tanzania \\ Email: muruganbama.thirumalai@gmail.com
}

How to cite this paper: Thirumalai, M. (2020) Quantitative Estimation of Acid and Base from Locally Available Materials by Using Titration Method. Open Access Library Journal, 7: e6400. https://doi.org/10.4236/oalib.1106400

Received: May 7, 2020

Accepted: June 12, 2020

Published: June 15, 2020

Copyright $\odot 2020$ by author(s) and Open Access Library Inc.

This work is licensed under the Creative Commons Attribution International License (CC BY 4.0).

http://creativecommons.org/licenses/by/4.0/

(c) (i) Open Access

\begin{abstract}
Purpose: In this paper, the estimation acid and base from locally available materials were studied. The main purpose of this research was to study to implement the use of locally available materials in secondary education especially in developing countries like Tanzania, in case of titration process; then to develop an idea on extracting locally available material (Acid from Lemons and Base from wood ashes) during the titration process in secondary education; and also to impart ability to the student on conducting titration process (experiment) by using a real physical existence of locally available materials. Methodology: Squeeze the lemons and strain the lemon juice to remove any pulp into the beaker. Add distilled water to the lemon juice inside the flask up to calibration mark. Hardwood ashes and red cabbage were sorted, cleaned and processed into boiled and cooled liquid extract. The extracts obtained were analyzed for titration process. Results: Quantitative Estimation of weak acid (Lemon) with strong base (Wood ashes) using titration method and red cabbage solution operate as an indicator and the end point determines the color changing from green to colorless.
\end{abstract}

\section{Subject Areas}

Analytical Chemistry

\section{Keywords}

Qualitative Estimation, Titration Method, Base, Acid, Locally Available

Materials, Lemon Fruit, Wood Ashes, Red Cabbage and Cassava Plant Leaf

\section{Introduction}

Titration method is a technique where solution of known concentration is used to determine the concentration of unknown solution. Typically the "Titrant" is known solution which is added in pipette, and "Analyte" is the unknown solu- 
tion which is added in burette. Bases are the substance that dissolves in water to release $\left(\mathrm{OH}^{-}\right)$into a solution. Bases are classified into two types that are weak base and strong base. This is according to [1] whereby strong base is substance which is ionized completely to form $\left(\mathrm{OH}^{-}\right)$ions as only negative charge when in solution. Example: $\left(\mathrm{K}_{2} \mathrm{CO}_{3}\right)$ from wood ashes. Weak base is substance which is ionized slightly to form $\left(\mathrm{OH}^{-}\right)$ions as only negative charge when in solution. Example: ammonium hydroxide.

Acid is a compound that can form hydrogen ions when dissolving in water to release $\left(\mathrm{H}^{+}\right)$ions into solution as only positive charge ion. Acid is classified into two types that are weak acid and strong acid. According to [1] whereby weak acid is substance which is ionized partially when dissolved in a solution. Example: $\left(\mathrm{C}_{6} \mathrm{H}_{8} \mathrm{O}_{7}\right)$ citric acid from lemon fruits. And strong acid is substance which is ionized completely when dissolved in a solution. Usually the titration of strong base and week acid use phenolphthalein indicator, locally indicator prepared from a Red Cabbages, hence an indicator is substance which changes color during the titration [2].

Generally acidic and basic titration goal is usually to use the substance of known concentration to determine the concentration of unknown concentration of the other substance [3].

Locally available materials: these are the materials which are (household materials) or sometimes called as low cost materials. In this titration the materials used are lemon as weak acid and wood ashes as strong base; note lemon produce (citric acid), wood ashes produce (potassium hydroxide) and red cabbages (as an indicator) [Figure 1].

The titration of weak acid and strong base are very common in secondary schools; thus it is why we concentrate on it. Due to expensiveness of chemicals substance (solution) like $\left(\mathrm{K}_{2} \mathrm{CO}_{3}\right)$ and other acids like citric acid, we decided to use locally available materials on making the proceeding of titration in secondary school with low coast. Therefore different authors and scholars explain many titrations, by using the other chemical substances from industries which are very expensive and toxic.

[4], defined process of determining the concentration of dissolved substance in terms of the smallest amount, of reagent known concentration required to bring about a given effect in chemical reaction with a known about volume of the lest solution.

[5], defined titrimetry is a common laboratory method of quantitative chemical analysis that is used to determine the unknown concentration of an identified analyte, a known concentration and volume of titrant reaction with a solution of analyte or titrant to determine with a solution of analyte or titrant to determine concentrations [6].

\section{Materials and Methodology}

\subsection{Methodology Used}

Methodology according to Dictionary.com methodology is asset or system of 
method, principle and rule for regulating and given discipline, as in art or science. According to Merriem-webster.com [4] is a body of methods, rules and postulates employed by discipline.

The followings are the methods that may be used over this project concerning this are:

- Extraction Method

- Preparation Method

- Titration Method

Extraction Method is a way of separating desirable substance when it is mixed with other. The mixture is brought into contact with solvent in which the substance of interest is soluble but the other substances are insoluble. Example extraction of $\mathrm{K}_{2} \mathrm{CO}_{3}$ (potassium carbonate) from hard wood Ashes based in research concerning.

Basic solution $\left(\mathrm{K}_{2} \mathrm{CO}_{3}\right)$.

Before the preparation of basic solution we must first prepare the potassium carbonate salt, from the hard-wood ashes.

Preparation Method is a process of making and designing the possible things, in order to do experiments. Example preparation of Lemon Juice from (Lemon), and Preparation of Red cabbage solution from (Red-cabbage).

Titration Method is a technique or process of estimating or determining unknown concentration from known concentration, or is all about Titrant, Analyte and Indicator which used to show color changes when in each mentioned. Example determination of unknown Lemon Juice Concentration by titrating with Potassium carbonate solution with help of Red-cabbage indicator [7] [8].

\subsection{Materials Used}

Materials are those equipment or concrete object which used to stimulate and promoting the learning and teaching activities, therefore in our research we use the following materials (Figure 1):
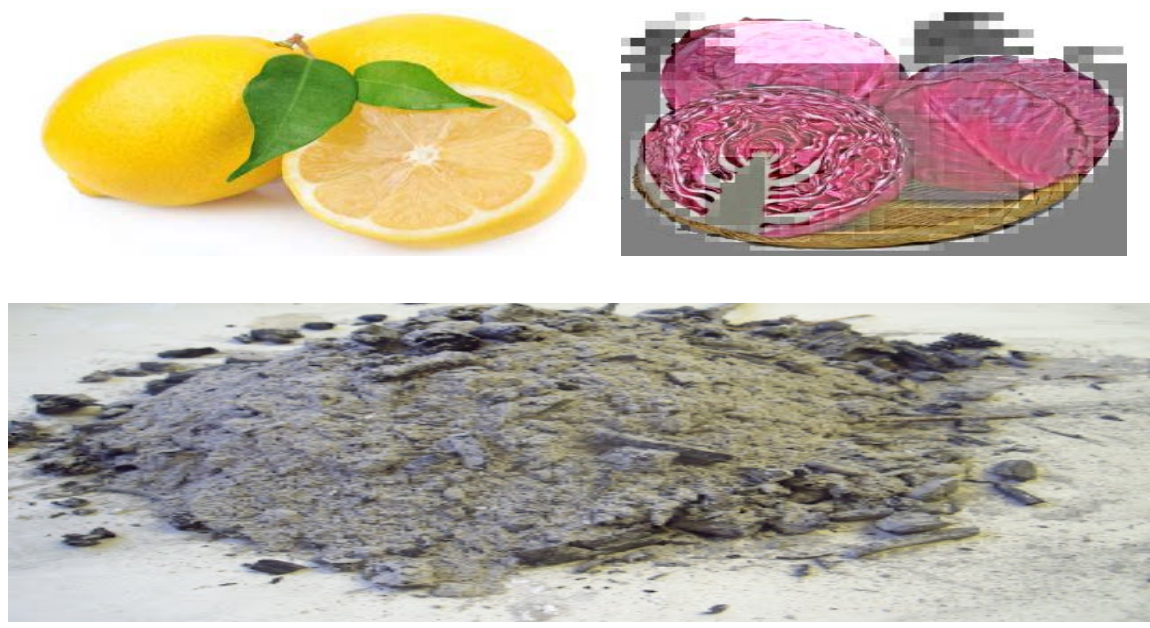

Figure 1. Material sample [9]. 


\section{Materials}

- Lemon

- Wood ashes

- Red-cabbage

- Distilled water

\subsection{Work Designing}

Project design is the capability to model, explore, and optimize complex projects and programs for teams to design their projects before committing to action.

Figure 2 is the table of specification as designed [10] [11].

\section{Result and Discussion}

\section{Result}

This called as (Upshot) is the final consequence of a sequence of actions or events expressed qualitatively or quantitatively. Possible results include advantages and disadvantages, gain, injury, loss, value and victory.

There are maybe a range of possible outcomes associated with an event depending on the point of view, historical distance or relevance. Reaching no result can mean that action is inefficient, ineffective, meaningless or flawed. The result is obtained by the following procedure

\section{Acid solution (Citric acid)}

The citric acid content of a lemon juice can be determined through a titration of the juice with strong base of known concentration.

1) Prepare at least 8 lemons and cut into equal two parts for each lemon.

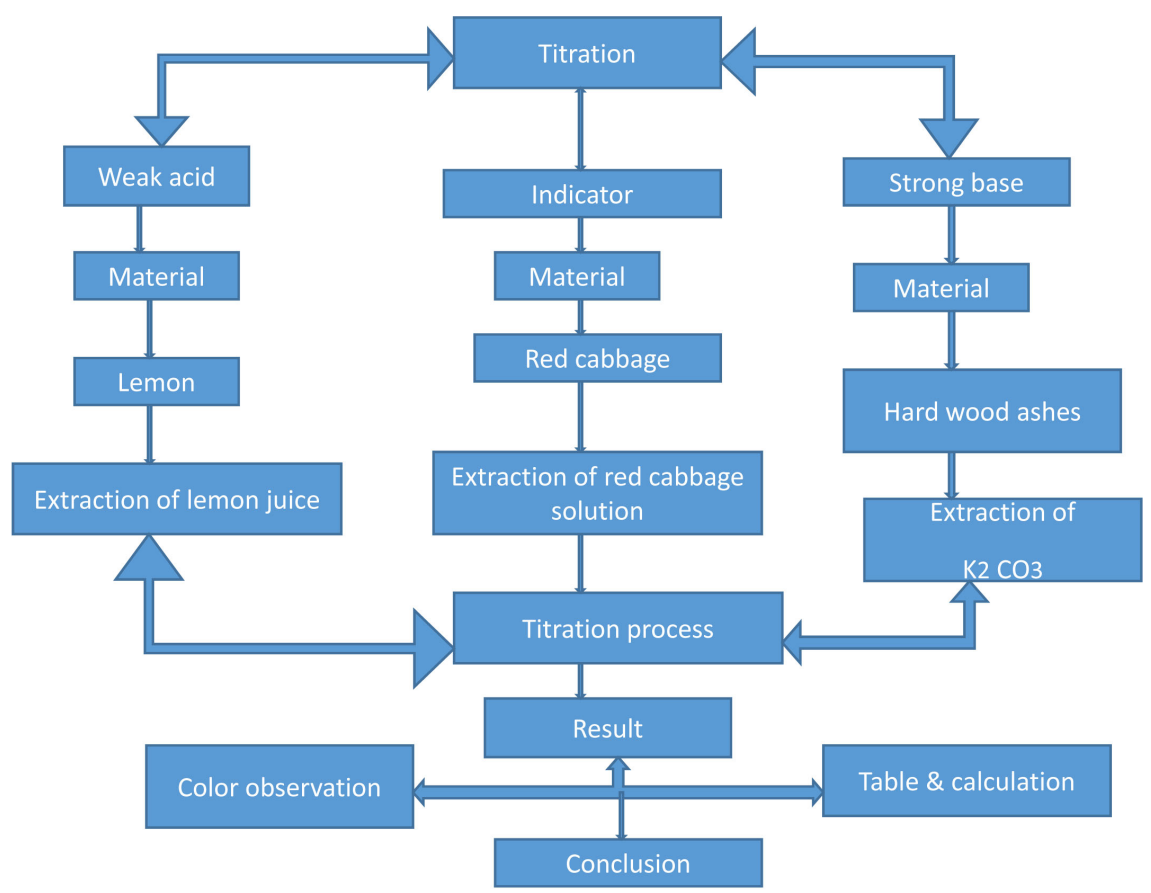

Figure 2. Flow chart of work designing. 
2) Squeeze the lemons and strain the lemon juice to remove any pulp into the $250 \mathrm{~mL}$ beaker.

3) Measure exactly $200 \mathrm{~mL}$ of lemon juice into the $1000 \mathrm{~mL}$ flat bottom flask.

4) Add about $800 \mathrm{~mL}$ of distilled water to the lemon juice inside the flask up to calibration mark.

5) Then cover to the top with stopper.

6) The flat bottom flask raised and inverting several times at least five times.

7) Keep the solution safe for experiment.

\section{Base sources}

Usually basic having characteristics of bitter and slippery, most of the basic substances are strong few of them is weak. The following are the source of strong Base: Hard \& soft wood-Ashes, gypsum, coconut, Banana fruits, Pawpaw Steam and Leaves, mushroom, and water melon. Therefore in our project we deal with Hard-wood Ashes [12].

Basic solution $\left(\mathrm{K}_{2} \mathrm{CO}_{3}\right)$

Before the preparation of basic solution first prepare the potassium carbonate salt, from the Hard-wood Ashes. The followings are the procedures of potassium carbonate salt preparation:

1) Take at least 500 gm of Hard-wood Ashes to add to Bucket and full with distilled water and stir.

2) Drain off water containing soluble substance into another Bucket.

3) Transfer the liquid into the saucepan and boil the liquid until enough water boiled away.

4) Then take the saucepan with the liquid out of the Heat source, and cool at room temperature.

5) After cooling filtrate again the solution, and leaving precipitate behind.

6) Transfer the Filtrate solution into large beaker and Heat again until (3/4) of water evaporated, then take out from the heat source and allow it to cool at room temperature.

7) Then after cooling filtrate again and take to the heat source and boil until all water Evaporated leaving the potassium carbonate salt on that Beaker. Then take it out from the sources.

8) Transfer the remained Sample into glass plate.

After preparing the potassium carbonate salt sample, the followings are the procedures of solution preparation of potassium carbonates in water:

1) Weigh $69 \mathrm{gm}$ of potassium carbonates solid, on the electronic balance.

2) Putt $69 \mathrm{gm}$ into $250 \mathrm{~mL}$ Beaker; add $50 \mathrm{~mL}$ of distilled water and stirring.

3) Transfer the solution into $1000 \mathrm{~mL}$ flat bottom flask and top up with distilled water up to graduated mark.

4) Then cover on the top by stopper, and risen and inverting several time at least five time.

5) Keep the solution for storage at safe place.

Red Cabbage solution (Indicator solution) 
1) After gathering red-cabbage, can make the red-cabbage $\mathrm{PH}$ indicator solution. As the following step:

2) Chop up the red-cabbage into small pieces, place into saucepan and cover with water.

3) Bring the solution to boil about 15 minutes and then turn off the heat, cool down for 30 minutes.

4) Pour the red-cabbage through strainer, to filter out all of the big chunks of the cabbage indicator liquid, into the compartment of the ice cube tray.

5) Keep safe the Red-cabbage solution (liquid) for experiment (Figure 3).

The followings are results of the research concerning (Titration) based into three:

- Indicator result.

- Basic extraction result.

- Table of result.

Indicator result: this is all about color change of an indicator when it is within the different samples (solution). Therefore: indicator used in this Project is Red-Cabbage; the following table shows the different results of Red-cabbage indicator when into different solutions (Table 1) [13].

\begin{tabular}{|c|c|c|c|c|c|c|}
\hline Ph & 2 & 4 & 6 & 8 & 10 & 12 \\
\hline Color & Red & Purple & Violet & Blue & Blue-Green & Greenish Yellow \\
\hline
\end{tabular}

Figure 3. Red cabbage ph indicator colors [14] [15].

Table 1. Indicator result.

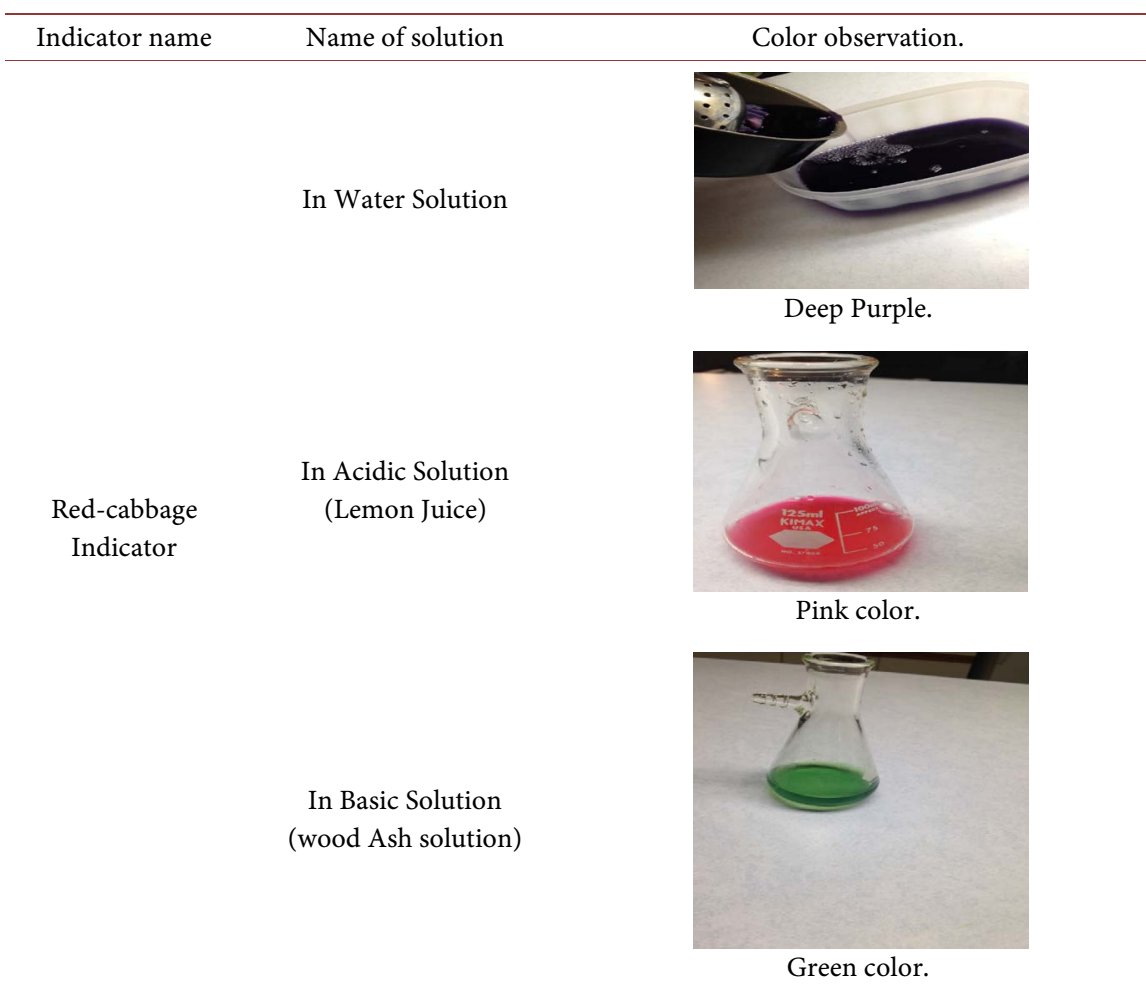


Basic extraction result: this is all about determination characteristics of extracted base which is $\mathrm{K}_{2} \mathrm{CO}_{3}$ from Wood ashes (Table 2).

Table of result: based on Titration process, this is outcome obtained from the titration process usually include collection of data in form of values (numbers) quantitative data and presented into table form. The table of result is obtained by the following procedure [16].

Make sure that, the apparatus is washed and properly arranged. Then fill the Lemon Juice (solution) into the Burette up to the graduate mark starting from zero and fix it to retort stand. Pipette $20 \mathrm{ml}$ of Potassium carbonate into a conical flask, then add two or three drops of red-cabbage indicator and shake properly Then Titrate and mark or record the end point of the reaction observed until reach the concordant value. Color changes from green to colorless [17].

\section{Table of result:}

Red cabbage indicator solution is used for titration.

The table of result of citric acid from (Lemon Juice) based on rate of time occurred are:

\section{Result: 1}

1) Lemon juice vs $\mathrm{K}_{2} \mathrm{CO}_{3}$ from (Ashes) immediate after sample prepared (Table 3).

Result: 2

2) Lemon juice vs $\mathrm{K}_{2} \mathrm{CO}_{3}$ from (Ashes) after 24 hrs (Table 4).

\section{Result: 3}

3) Lemon juice vs. $\mathrm{K}_{2} \mathrm{CO}_{3}$ from (Ashes) after $48 \mathrm{hrs}$.

If the Volume of Base $\left(\mathrm{K}_{2} \mathrm{CO}_{3}\right)$ from wood ashes is $20 \mathrm{ml}$ (Table 5).

Table 2. Basic extraction result.

\begin{tabular}{c}
\hline Name of Extracted Sample \\
\hline White Salt with colorless solution when in water \\
$\begin{array}{c}\text { Potassium Carbonate } \\
\left(\mathrm{K}_{2} \mathrm{CO}_{3}\right)\end{array}$ \\
It is deliquescent substance \\
It is appearing a wet or damp solid in production of soap and glass
\end{tabular}

Table 3. Lemon juice vs $\mathrm{K}_{2} \mathrm{CO}_{3}$ from (Ashes) immediate after sample prepared.

\begin{tabular}{ccccc}
\hline BURRET READING $\left(\mathrm{cm}^{3}\right)$ & PILOT $(\mathrm{ml})$ & $\mathbf{1}$ & $\mathbf{2}$ & $\mathbf{3}$ \\
\hline INITIAL READING & 00.00 & 00.00 & 22.50 & 00.00 \\
FINAL READING & 23.00 & 22.50 & 44.90 & 22.50 \\
TITRIAL VOLUME & 23.00 & 22.50 & 22.40 & 22.50 \\
\hline
\end{tabular}


Table 4. Lemon juice vs $\mathrm{K}_{2} \mathrm{CO}_{3}$ from (Ashes) after $24 \mathrm{hrs}$.

\begin{tabular}{ccccc}
\hline BURRET READING $\left(\mathrm{cm}^{3}\right)$ & PILOT $(\mathrm{ml})$ & $\mathbf{1}$ & $\mathbf{2}$ & $\mathbf{3}$ \\
\hline INITIAL READING & 00.00 & 00.00 & 25.00 & 00.00 \\
FINAL READING & 25.50 & 25.00 & 50.00 & 25.00 \\
TITRIAL VOLUME & 25.50 & 25.00 & 25.00 & 25.00 \\
\hline
\end{tabular}

Table 5. Lemon juice vs $\mathrm{K}_{2} \mathrm{CO}_{3}$ from (Ashes) after $48 \mathrm{hrs}$.

\begin{tabular}{ccccc}
\hline BURRET READING $\left(\mathrm{cm}^{3}\right)$ & PILOT $(\mathrm{ml})$ & $\mathbf{1}$ & $\mathbf{2}$ & $\mathbf{3}$ \\
\hline INITIAL READING & 00.00 & 00.00 & 24.50 & 00.00 \\
FINAL READING & 25.00 & 24.50 & 49.50 & 25.00 \\
TITRIAL VOLUME & 25.00 & 24.50 & 25.00 & 25.00 \\
\hline
\end{tabular}

\section{Conclusions and Recommendations}

\subsection{Conclusions}

Conclusion is an ending section which states the concluding ideas and conceptual of the proceeding writings. This generally follows the body or perhaps an afterword and the conclusion may be followed by an epilogue, outro and postscript.

According to the research concerning, it is concluded that in wood ashes, the best kind for many basic productions is hard wood-ashes (Ash from Timber, Big-Trees, Logs), rather than soft wood-ashes (Ash from grasses and papers).

Apart from all constituents present in wood-ashes like (sodium carbonate, potassium carbonate and other compounds like phosphorus, silicon), the common compound present in high concentration is Potassium Carbonate $\left(\mathrm{K}_{2} \mathrm{CO}_{3}\right)$.

Based on investigation the only red-cabbage species is used as an indicator among the cabbage species. Due to that, red-cabbage contains the pigment or coloring agent called anthocyanin [18]. This pigment is found in many flour fruits, fall leaves, and is responsible for many of the red blues and purple you see around you.

\subsection{Recommendations}

- Due to expensiveness of the sample-chemicals and indicators during the conduction of titration and other experiments, advice the government, should focus on locally available materials in order to develop other sample solutions, because it is possible.

- From the objective of titration to demonstrate the basic laboratory technique of titration and to learn how to calculate concentration based on titration, due to that as research member advice the government and private sectors to give the high support to all school teachers especially science teachers to use locally available materials in experiment in steady of advanced chemicals and give them motivation and reward for the best idea, this will help to high school performance in implementing curriculum and developing the stu- 
dents' skills based on home available materials and also help to reduce the high cost required by the chemical from other countries or from industries.

- The government and private sectors should join together to conduct exhibition concern with creativity of the different teachers from different schools maybe region to region or district to district or ward to ward on how locally available materials are used as concretes' materials in the implementing curriculum.

- Teachers of science should plan an inquiry-based science program for their students. These teachers should:

1) Develop a frame of the yearlong and short term goals for students.

2) Select science content and adopt and design curriculum to meet the interest, knowledge, understanding, ability and experience of students.

3) Select teaching and assessment strategies that support the development of the students' understanding and nurture a community of science learners. Work together as colleagues within and across discipline and grade levels.

\section{Conflicts of Interest}

The author declares no conflicts of interest regarding the publication of this paper.

\section{References}

[1] Savante Arrhinius 1884.

http://chemed.chem.purdue.edu/genchem/history/arrhenius.html

[2] Purba, M. (2009) Kimia. Erlangga. jakarta and purwant, bundidan Arinto Nugroho. 2008 Eksplorasi Alam I. Tigaserangkai.

[3] Kotz, J., Treichel, P., Townsend, J. and Treichel, D. (2013) Acids and Bases. Marcel Dekker Inc., New York.

[4] https://www.Merriam-webster.com

[5] https://en.wikipedia.org/wiki/Titration

[6] Russell, A.A. (2013) Chemistry with Computers. Vernier Software, Portland OR. Journal of Laboratory Chemical Education, 1, 34.

[7] Holdermned, A. (1987) Advanced Level Inorganic Chemistry. 6th Edition, Heirnemann Education Publication Publisher, Helley Court Jordon Hill Oxiford 0^28EJ Part of Person Education Limited.

[8] Tarr, D.A. and Miessler, G.L. (2004) Inorganic Chemistry. 3rd Edition, Reason Education, Singapore, Pte.ltd, India Brach 4\&2.F.J.E patpaurgenins Delhi, India.

[9] Hagen, T.F., Snorre, B., et al. (2011) Archltimarcoisdoring. Orca Operational Consultancy, The Pasvik Valley, Norway.

[10] USAID Glossary of Evaluation Terms, March 2009. (Sited from Dennis Bours, Punjanit Leagnavar, 2014 Work Project)

[11] (2010) UNAIDS Monitoring and Evaluation Fundamental.

[12] Zmdahl, S.S. and Zumdahl, S.A. (2003) Atomic Structure and Periodicity. In: Chemistry, 6th Edition, Houghton Mifflin Company, Boston, 290-294.

[13] https://www.stevespanglerscience.com/lab/experiments/red-cabbage-chemistry 
[14] http://www.sciencekiddo.com/red-cabbage-ph-Indicator

[15] Meaconopsis Group (2017) Colourrange. Retrieved IC February.

[16] Jayelata, D., Vidya, S. and Sumath, S. (2006) Laboratory Worce for Engineering Chemistry Practical Dhanam Pub Cariow Chemistry. 4th Edition, S. Chand \& Co., Ltd., New Delhi.

[17] Christian, G.N. (2007) Analyitical Chemistry. 6th Edition, John Wiley and Sons, Inc., Noida.

[18] Davies, K.M. (2004) Plant Pigment and Their Manipulation. Wiley-Blackwell, Hoboken. 